CLINICAL STUDY

\title{
Body composition is distinctly altered in Turner syndrome: relations to glucose metabolism, circulating adipokines, and endothelial adhesion molecules
}

\author{
Claus Højbjerg Gravholt ${ }^{1}$, Britta Eilersen Hjerrild ${ }^{1}$, Leif Mosekilde ${ }^{2}$, Troels Krarup Hansen ${ }^{1}$, \\ Lars Melholt Rasmussen $^{3}$, Jan Frystyk ${ }^{1}$, Allan Flyvbjerg ${ }^{1}$ and Jens Sandahl Christiansen ${ }^{1}$ \\ ${ }^{1}$ Medical Research Laboratories, Medical department M (Endocrinology and Diabetes), Aarhus Sygehus NBG, and Department of ${ }^{2}$ Endocrinology and \\ Metabolism and ${ }^{3}$ Clinical Biochemistry, Aarhus Sygehus THG, Aarhus University Hospital, DK-8000 Aarhus C, Denmark
}

(Correspondence should be addressed to C H Gravholt; Email: ch.gravholt@dadlnet.dk)

\begin{abstract}
Background: Body composition in Turner syndrome (TS) is altered with final height of TS decreased; anthropometry and bone mass distinctly changed.

Aim: To describe total and regional distribution of fat and muscle mass in TS and the relation to measures of glucose metabolism, sex hormones, IGFs, and markers of inflammation and vascular function.

Material and methods: Fifty-four women with TS (mean age, $42.5 \pm 9.7$ years) and an age-matched group of controls $(n=55)$ were examined by dual-energy X-ray absorptiometry scans with determination of regional body composition and estimation of visceral fat and skeletal muscle mass. We determined maximal oxygen uptake and assessed physical activity using a questionnaire. We measured serum adiponectin, ghrelin, IGF-I, IGF-binding protein-3 (IGFBP-3), estradiol, testosterone, sex hormone-binding globulin (SHBG), insulin, glucose, cytokines, vascular cell adhesion molecule-I, and intercellular cell adhesion molecule-I. Insulin sensitivity was estimated. Multiple linear regression models were used to examine the relationships between variables.

Results: TS had lower total lean body mass (LBM), while body mass index (BMI) and total fat mass (FM) were increased. We found increased visceral FM, and decreased trunk LBM, appendicular LBM, and skeletal muscle mass. $\mathrm{VO}_{2 \max }$ and physical activity were significantly lower in $\mathrm{TS}$, as were most hormone levels, except increased leptin. In multiple linear regression models, status (i.e. TS or control) was a consistent contributing variable.

Conclusion: Profound changes are present in body composition in TS, with increased FM, and decreased skeletal muscle mass. Circulating hormones, $\mathrm{VO}_{2 \max }$, and insulin sensitivity influence body composition. The accumulation of visceral fat would predict a higher risk of development of the insulin resistance syndrome.
\end{abstract}

European Journal of Endocrinology 155 583-592

\section{Introduction}

Body composition is altered in Turner syndrome (TS). Accordingly, the final height of Turner patients is approximately $20 \mathrm{~cm}$ below that of the average female population, and the anthropometrical composition of women with TS is very distinct (1-3). Turner females are primarily growth retarded along the longitudinal axis, while the horizontal measurements are comparable to those of control females (1-3). This means, while height, sitting height, and arm-span are reduced by approximately 3-4 SDS compared with a reference population, hands and feet are reduced in size to a lesser extent, while head circumference, biacromial and biiliacal diameter are comparable to those of healthy women. Fat mass (FM) and body mass index (BMI) have been found to be higher in adult Turner patients compared with agematched controls, and lean body mass (LBM) is inappropriately low $(4,5)$. In addition, distinct differences in regional body composition was present in young TS girls ( $9-15$ years) in comparison with age- and BMI-matched controls in two different study groups $(6,7)$, and in adults excess visceral fat and hepatic adipose tissue have been documented (8). Therefore, TS has been characterized as a syndrome of disproportionate anthropometry and body composition (7).

Glucose metabolism is altered in TS and type 2 diabetes is seen frequently (9); insulin resistance has been reported in some studies on children $(10,11)$, while studies on adults have pointed towards $\beta$-cell failure rather than insulin resistance as the primary defect in glucose homeostasis $(5,12,13)$. The pathogenesis 
behind progressive $\beta$-cell failure is not clear, and further characterization is necessary.

Women with TS suffer from an increased risk of cardiovascular disease, hypertension and stroke $(9,14)$, and aortic dissection is seen frequently and at a young age (15), visualizations often show aortic abnormalities (16), and it has been suggested that intrinsic biochemical abnormalities may be present in the aortic wall. Adhesion factors are secreted from endothelial cells and levels are increased in response to insults to the vasculature. A recent study has implicated an increased level of interleukin (IL) 6 in TS (17), and we have previously shown in different populations of females with TS that C-reactive protein (CRP) is discretely increased (18), pointing towards an activated inflammatory state.

Here, we further characterize the relationships between body composition, glucose metabolism, sex hormones, insulin -like growth factors (IGFs) and markers of inflammation, and vascular function in TS.

\section{Materials and methods}

\section{Subjects}

The study group consisted of 54 patients with TS, diagnosed by chromosome analysis. Karyotypes were distributed as follows: 45,X $(n=25) ; 45, \mathrm{X} / 46, \mathrm{XX}$ $(n=5)$; karyotypes with isochromosomes (Xq) or deletions $(n=14)$; karyotypes with $\mathrm{Y}$ chromosome material $(n=5)$; karyotypes with a marker or ring chromosome $(n=5)$.

All patients were recruited through the National Society of Turner Contact Groups in Denmark. Inclusion involved mailing letters by the National Society to all 90 members above 20 years of age. A total of 54 chose to participate. Exclusion criteria were untreated hypothyroidism or hyperthyroidism, present or past malignant diseases, clinical liver disease, or treatment with drugs known to interfere with glucose homeostasis or fat metabolism (e.g. glucocorticoids). Five of the patients had menstruated spontaneously and forty-five received conventional sex hormone-replacement therapy (HRT) consisting of $17 \beta$-estradiol ( $2 \mathrm{mg}$ ) for the entire cycle and norethisterone $(1 \mathrm{mg})$, medroxyprogesterone $(10 \mathrm{mg})$, or levonorgestrel $(0.25 \mathrm{mg})$ for 10 days every cycle. Two of the five women with spontaneous menstruations were still menstruating, while the other three experienced premature ovarian failure and received HRT. Five patients had chosen not to receive HRT. All were interviewed concerning the age at menarche (if present), start of induction of puberty (by exogenous estrogen), premature menopause (if present), duration of HRT, and cessation with HRT (when relevant), enabling summation of total estrogen exposure (in years). These variables were used in subsequent statistical computations. There were no differences in any dual-energy X-ray absorptiometry (DEXA) or biochemical parameters between estrogen exposed and unexposed patients, except a lower level of serum estradiol, as expected. We therefore chose to combine the two groups in all further computations.

A control group of 55 healthy women between 20 and 79 years of age was also included in the study. None of the controls had been treated with, or were presently receiving HRT. All subjects received oral and written information concerning the study prior to giving written informed consent. The protocol was approved by the Aarhus County Ethical Scientific Committee as an extension of a previous protocol (no. 1994/2929).

\section{Methods}

Participants were examined in the morning. Women were instructed not to eat or drink anything else other than bottled mineral water and met fasting in the laboratory. After blood was drawn, serum was immediately separated and stored at $-20{ }^{\circ} \mathrm{C}$ in multiple vials for later analysis. Body weight was measured to the nearest $0.1 \mathrm{~kg}$ on an electronic scale, and body height to the nearest $0.5 \mathrm{~cm}$, with the subjects in underwear and barefooted. BMI was calculated as weight $(\mathrm{kg})$ divided by height $(\mathrm{m})$ squared, and body surface area according to the DuBois equation: $S=0.007184 \times$ weight $^{0.425} \times$ height ${ }^{0.725}$, where weight was in $\mathrm{kg}$, height in $\mathrm{cm}$, and $S$ is expressed in $\mathrm{m}^{2}$ (Table 1).

A 6-min sub-maximal exercise test with continuous monitoring of the heart rate was performed on a bicycle ergometer (Monark Ergometric 829 E, Monark exercise $\mathrm{AB}$, Varberg, Sweden) using a workload of $300-1200 \mathrm{kpm} / \mathrm{min}$, depending on age and reported physical activity by the subject. The mean heart rate

Table 1 Number and age of participants, anthropometric and measures of physical fitness in Turner syndrome (TS) patients and in normal women (controls). Values are given as mean \pm s.D., unless otherwise indicated.

\begin{tabular}{|c|c|c|c|}
\hline & $\begin{array}{c}\text { TS } \\
(n=54)\end{array}$ & $\begin{array}{c}\text { Controls } \\
(n=55)\end{array}$ & $\boldsymbol{P}^{*}$ \\
\hline Age (years) & $42.5 \pm 9.7$ & $41.9 \pm 10.3$ & 0.8 \\
\hline $\begin{array}{l}\text { Estrogen exposure } \\
\text { (years) }\end{array}$ & $20.8 \pm 8.9$ & - & - \\
\hline Height $(\mathrm{cm})$ & $146.0 \pm 6.7$ & $167.5 \pm 5.6$ & $<0.001$ \\
\hline Weight (kg) & $58 \pm 14$ & $66 \pm 9$ & 0.001 \\
\hline BMI $\left(\mathrm{kg} / \mathrm{m}^{2}\right)$ & $27.2 \pm 5.5$ & $23.5 \pm 2.8$ & $<0.001$ \\
\hline Surface area $\left(\mathrm{m}^{2}\right)$ & $1.49 \pm 0.18$ & $1.74 \pm 0.12$ & $<0.001$ \\
\hline $\begin{array}{l}\text { Physical activity } \\
\text { index }^{\dagger}\end{array}$ & $2(0-5)$ & $3(0-7)$ & $0.001^{\ddagger}$ \\
\hline $\begin{array}{l}\mathrm{VO}_{2 \max } \\
\text { Systolic blood } \\
\text { pressure }(\mathrm{mmHg})^{\dagger}\end{array}$ & $\begin{array}{r}36.0 \pm 10.3 \\
130(85-195)\end{array}$ & $\begin{array}{c}40.1 \pm 9.2 \\
118(94-176)\end{array}$ & $\begin{array}{l}0.04 \\
0.005\end{array}$ \\
\hline $\begin{array}{l}\text { Diastolic blood } \\
\text { pressure }(\mathrm{mmHg})^{\dagger}\end{array}$ & $82(55-120)$ & $78(60-96)$ & 0.2 \\
\hline
\end{tabular}

${ }^{\star} t$-Test, unless otherwise indicated. ${ }^{\dagger}$ Data presented as median and range. ‡Mann-Whitney test.

BMI, body mass index. 
during the last $2 \mathrm{~min}$ of work ( $>120$ beats/min) was used for calculation of the maximal aerobic capacity $\left(\mathrm{VO}_{2 \max }\right)$ (19). This indirect measure of maximal aerobic capacity has been shown to correlate well with a direct measure of maximal aerobic capacity, with a coefficient of variation (CV) of less than 10\% (20), which in our lab has a day-to-day intra-individual $\mathrm{CV}$ of 9\% (unpublished observations). Participants were interviewed concerning their level of daily activity, during work, leisure, and sports, and the results quantified using a questionnaire as previously described (21), and a combined index of physical activity is presented.

We measured total and regional FM (g), and LBM (g) by DEXA using a Hologic QDR scanner (Hologic, Inc., Waltham Mass, version 7.20D) in pencil-beam mode. The system software provided the mass of lean body, fat and bone mineral for the whole body and specific regions. Appendicular, trunk and visceral trunk FM, and trunk and appendicular LBM were extracted. Visceral FM was determined manually after placement of a region of interest from L2 to L4 and laterally extending to the outer rim of the rib cage (22), an area shown to contain predominantly visceral adipose tissue (23). Appendicular LBM measured by DEXA correlates well with estimates determined by total potassium and nitrogen (24), and intermuscular adipose tissue-free (IMAT) skeletal muscle mass (SM) was then estimated according to a recently developed, magnetic resonance imaging (MRI)-based, and validated prediction model with minimal variation (25) as IMAT $\mathrm{SM}=-0.14+$ $1.18 \times$ appendicular LBM (in $\mathrm{kg}$ ) $-0.03 \times$ age. Crosscalibration was insured through the use of double measurements and a common phantom as described previously (26). The CV values for the actual QDR scanner was less than $2 \%$ for any region from repeat measurements in 18 subjects, and long-term stability has been shown to be high with changes less than $0.2 \%$ per year. These figures included cross-over calibration, change of hardware, change of technicians, and longterm stability (26). Insulin sensitivity was assessed using the homeostatic model assessment (HOMA-index) modeling, based on simultaneously sampled fasting levels of glucose and insulin. The HOMA2 computer model was downloaded from http://www.dtu.ox.ac.uk/ index.html? maindoc $=/$ homa $/$ download $/ \mathrm{html}$.

\section{Assays}

We measured serum total adiponectin by a novel in-house time-resolved immunofluorometric assay (TR-IFMA), and serum ghrelin was determined by an in-house RIA, as described previously $(27,28)$; within and between assay $\mathrm{CV}$ values of standards and unknown samples averaged $<5$ and $10 \%$ respectively. Serum IGF-I was measured by noncompetitive TR-IFMA, and IGF binding protein (IGFBP)-3 by IRMA (Diagnostics Systems Laboratories, Inc., Webster, TX,
USA). For IGF-I, the detection limit was $2.7 \mu \mathrm{g} / \mathrm{l}$ and the intra-and interassay CV values were $<5$ and $<10 \%$ respectively. Serum estradiol and testosterone were measured by a commercial time-resolved fluoroimmunoassay (Dissociation-Enhanced Lanthanide FluoroImmunoassay (DELFIA), Wallac, Inc., Turku, Finland). Insulin was determined by commercial ELISA (DAKO, Glostrup, Denmark). Serum sex hormone-binding globulin (SHBG) was measured by a commercial timeresolved fluoroimmuno assay DELFIA (Wallac Oy, Turku, Finland). The cytokines IL-1 $\beta$, IL-2, IL-4, IL-6, IL-8, IL-10, tumor necrosis factor (TNF)- $\alpha$, interferon (IFN)- $\gamma$, and granulocyte-macrophage colony-stimulating factor (GM-CSF) were measured with a Luminex Suspension Array System (Bio-Plex, Bio-Rad Laboratories Inc., Ca, USA), in which sandwich ELISA captured antibodies are coupled to color-coded beads, permitting the simultaneous determination of several different cytokines as identity and amount of analyte are read by separate lasers in a flow-based, dual-laser array reader (29). The detection level for all cytokines was $1 \mathrm{ng} / \mathrm{l}$. All values below the detection limit were set to $1 \mathrm{ng} / \mathrm{l}$. Intra- and inter assay CV values were below $6 \%$ and in the range of $11-17 \%$ respectively. Serum vascular cell adhesion molecule-I (VCAM-1) and intercellular cell adhesion molecule-I (ICAM-1) were measured by commercially available ELISA kits, as described by the manufacturer (R\&D Systems, Minneapolis, MN, catalog no. DY809, VCAM-1; catalog no. DY720, ICAM-1).

\section{Statistical analysis}

All statistical calculations were carried out using SPSS for Windows version 13.0 (SPSS, Inc., Chicago, Illinois, USA). Data were examined by Student's two-tailed unpaired $t$-test or the Mann-Whitney $U$-test, where appropriate. General linear model (GLM) ANOVA was used to compute adjusted estimates of body composition as this method allows for the removal of the linear effects of covariates on the dependent variable. Using GLM ANOVA, body composition variables were adjusted for weight and status (i.e. being TS or control), and the mean \pm s.E.M. adjusted values are presented. Pearson's correlation was used to examine relations between different measures of body composition, while Spearman's correlation to examine the relationships between estimates of body composition, circulating sex steroids, cytokines, indices of glucose homeostasis, and growthrelated parameters. Backward multiple linear regression was used to examine the principal determinants of estimates of body composition, where independent variables were omitted from the model when $P>0.1$. Results were expressed as mean \pm s.D., or median and range when data were not parametrically distributed. Levels less than $5 \%$ were considered to be significant. 


\section{Results}

\section{Anthropometry, body composition, and physical activity}

Women with TS were smaller, as indicated by decreased height, weight, total LBM, weight and status-adjusted total LBM, and body surface area, while BMI, total FM and weight, and status-adjusted total FM was increased (Table 2). Distinct differences in regional body composition were present, with increased visceral FM and decreased trunk and appendicular LBM and estimated IMAT SM. Adjusted values showed increased regional FM and decreased LBM with a resultant change in the ratio of trunk to appendicular FM and LBM in TS (Table 1). Relations between FM and LBM were changed in TS with tight positive correlations between total, visceral, and appendicular FM and LBM respectively, while such significant relations were absent in controls (Fig. 1).

$\mathrm{VO}_{2 \max }$ and physical activity was significantly lower among TS women. There was a strong relationship between $\mathrm{VO}_{2 \max }$ and LBM, both total and regional, in both TS and controls (all $r>0.4$, all $P<0.005$ ). The relationship between $\mathrm{VO}_{2 \max }$ and IMAT SM was even stronger (TS: $r=0.51, P=0.001$; controls: $r=0.70$, $P<0.001)$. However, the nature of this relation between measures of LBM and $\mathrm{VO}_{2 \max }$ was significantly different in the two study groups (Fig. 2), with the slope of the regression line being significantly different between groups (results not shown). The physical activity index, but not $\mathrm{VO}_{2 \max }$, was negatively correlated to measures of body adiposity by DEXA (all $r<-0.3$, all $P<0.03$ ) in both TS and controls. $\mathrm{VO}_{2 \max }$ and the physical activity index were correlated in both TS and controls (TS: $r=0.4, P=0.02$; controls: $r=0.4, P=0.003$ ).

Women with TS started HRT at a median age of 18 (13-60) years with an average treatment time of 20 years. There was no significant relationship between estrogen exposure in years in TS and estimates of body composition, or $\mathrm{VO}_{2 \max }$.

\section{Glucose homeostasis, IGFs and sex hormones}

Fasting glucose was slightly increased, while fasting insulin and HOMA-index was similar in TS and controls (Table 3). Leptin levels increased in TS, while IGF-I, IGFBP-3, testosterone, SHBG, and ghrelin decreased, and estradiol was comparable in TS and controls (Table 4).

\section{Cytokines}

Circulating adiponectin was similar in TS and controls, despite the profound differences in body composition, whereas levels of IL- 6 , IL-8, and TNF- $\alpha$ were significantly elevated in TS (Table 3). The remaining cytokines were comparable in TS and controls. Adiponectin correlated significantly and inversely with measures of adiposity in TS but not in controls (Fig. 3C).

\section{Endothelial factors}

Circulating VCAM-I was similar in TS and controls, while ICAM-I was significantly elevated in TS (Table 4).

\section{The effect of karyotype}

There was no statistical difference in any of the studied parameters when comparing the group of women with the classical 45, $\mathrm{X}$ karyotype and the group of women comprising all other karyotypes.

\section{Relationships between body composition and biochemical markers}

Total and regional FM correlated significantly and positively with HOMA-index, insulin, leptin, and negatively with adiponectin and ghrelin $(r>0.5$, all $P<0.001)$ in TS, and positively with HOMA-index, insulin, and leptin in controls $(r>0.3$, all $P<0.04)$, but not with adiponectin and ghrelin (Fig. $3 \mathrm{~A}$ and $\mathrm{B}$ ).

There were no significant correlations between the remaining cytokines and measures of body composition

Table 2 Body composition data derived from whole body dual-energy X-ray apsorptiometry (DEXA) scans in Turner syndrome (TS) patients and normal women (controls). Values are given as mean \pm s.D., unless otherwise indicated.

\begin{tabular}{|c|c|c|c|}
\hline & TS $(n=54)$ & Controls $(n=55)$ & $\boldsymbol{P}^{*}$ \\
\hline Total fat mass $(\mathrm{FM})(\mathrm{kg})$ & $22.1 \pm 9.0$ & $20.6 \pm 7.3$ & 0.4 \\
\hline Adjusted total FM $(\mathrm{kg})^{f^{\prime}}$ & $24.5 \pm 0.5$ & $18.3 \pm 0.5$ & $<0.001$ \\
\hline Total lean body mass (LBM) $(\mathrm{kg})$ & $35.4 \pm 5.7$ & $44.2 \pm 4.7$ & $<0.001$ \\
\hline Adjusted LBM $(\mathrm{kg})^{\dagger}$ & $36.7 \pm 0.5$ & $42.9 \pm 0.5$ & $<0.001$ \\
\hline Adjusted appendicular FM $(\mathrm{kg})^{\dagger}$ & $11.6 \pm 0.2$ & $10.2 \pm 0.2$ & $<0.001$ \\
\hline Adjusted appendicular LBM $(\mathrm{kg})^{\dagger}$ & $14.1 \pm 0.3$ & $17.4 \pm 0.3$ & $<0.001$ \\
\hline Trunk/appendicular FM & $0.97 \pm 0.28$ & $0.75 \pm 0.25$ & $<0.001$ \\
\hline Trunk/appendicular LBM & $1.37 \pm 0.14$ & $1.25 \pm 0.09$ & $<0.001$ \\
\hline Visceral FM $(\mathrm{kg})^{\ddagger}$ & $1.75 \pm 0.93$ & $1.59 \pm 0.70$ & 0.3 \\
\hline Adjusted visceral FM $(\mathrm{kg})^{\dagger \ddagger}$ & $2.00 \pm 0.06$ & $1.35 \pm 0.06$ & $<0.001$ \\
\hline Skeletal muscle mass (kg) & $14.6 \pm 3.2$ & $19.8 \pm 2.9$ & $<0.001$ \\
\hline Adjusted skeletal muscle mass $(\mathrm{kg})^{\dagger}$ & $15.2 \pm 0.3$ & $19.1 \pm 0.3$ & $<0.001$ \\
\hline
\end{tabular}

${ }^{*}$ Independent $t$-test. ${ }^{\dagger}$ Adjusted for weight and status (i.e. being TS or control); mean and standard error of the mean is presented. ${ }^{\ddagger}$ Estimated after placement of a new region of interest on the whole body DEXA scan (see Materials and methods for further information). 

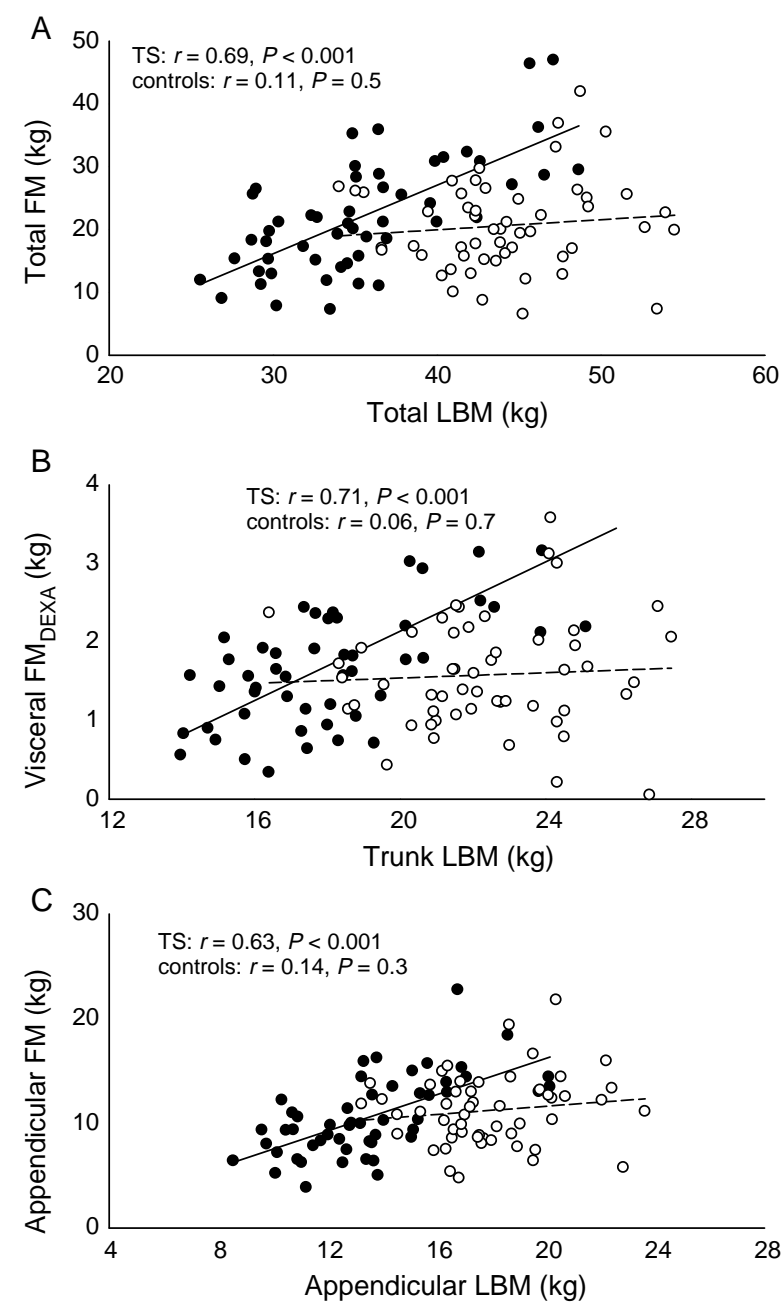

Figure 1 The relation between (A) total fat mass (FM) and lean body mass (LBM), (B) trunk FM and LBM, and (C) appendicular FM and LBM in TS ( $O$ and - ) and controls ( $O$ and ---- ). Regression coefficient and significance levels are indicated in each graph.

in TS and controls. Likewise, there were no significant correlations between markers of endothelial function and measures of body composition except for a significant negative correlation between VCAM and measures of body fat $(r>-0.28$, all $P<0.04)$ in controls.

In individuals with TS, IGF-I, IGFBP-3, testosterone, and insulin were significantly and positively correlated with IMAT SM (all $P<0.02$ ) and other measures of LBM, and SHBG was negatively correlated $(P=0.02)$ (Fig. 4). These relations were similar but not significant in controls, and indeed, the regression lines were distinctly different with the regression line for controls being shifted upwards, which could be indicative of a relative resistance to the anabolic effect of these hormones in TS. On the other hand, estradiol correlated positively with IMAT SM $(P=0.04)$ and other measures of LBM in controls.

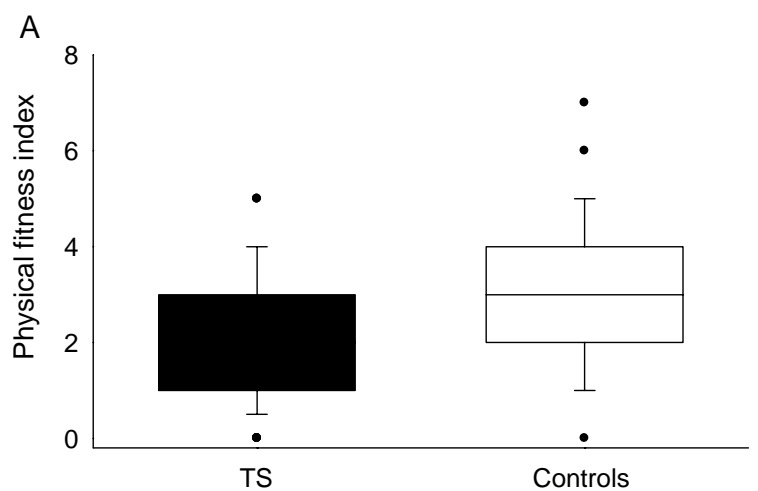

B

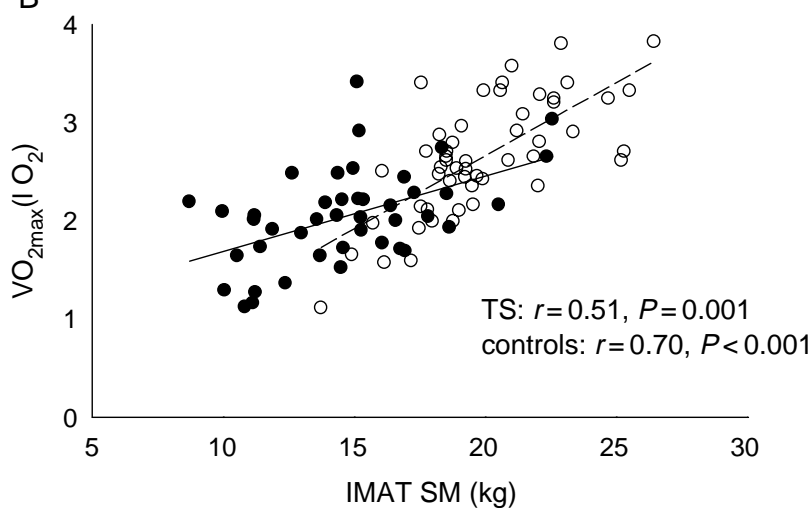

Figure 2 (A) Physical fitness index in women with TS (black bars) and controls (open bars). Outliers are indicated as dots. (B) The relationship between $\mathrm{VO}_{2 \max }$ and intermuscular adipose-free tissue skeletal muscle mass (IMAT SM) in TS ( and - ) and controls $(\bigcirc$ and ---- ). Regression coefficient and significance levels are indicated on the graph.

Table 3 Circulating adipokines and measures of glucose homeostasis in Tumer syndrome (TS) patients and controls (mean \pm s.D., geometric mean $\%$ - antilog S.D., or median and range).

\begin{tabular}{|c|c|c|c|}
\hline & $\begin{array}{c}\text { TS } \\
(n=54)\end{array}$ & $\begin{array}{c}\text { Controls } \\
(n=55)\end{array}$ & $\boldsymbol{P}^{\dagger}$ \\
\hline $\begin{array}{l}\text { Adiponectin } \\
(\mathrm{mg} / \mathrm{l})\end{array}$ & $11.2(3.2-32.9)$ & $11.6(5.9-34.1)$ & 0.8 \\
\hline $\mathrm{IL}-1 \beta(\mathrm{ng} / \mathrm{l})$ & $1.0 * /-1.2$ & $1.2^{*} /-1.8$ & 0.9 \\
\hline IL-2 (ng/l) & $1.3^{\star} /-2.2$ & $1.4^{*} /-3.1$ & 1.0 \\
\hline IL-4 (ng/l) & $1(-)$ & $1.1^{*} /-2.0$ & 0.2 \\
\hline IL-6 (ng/l) & $2.5^{\star} /-3.2$ & $1.6^{\star} /-3.3$ & 0.001 \\
\hline IL-8 (ng/l) & $11.2^{*} /-6.4$ & $7.7^{\star} /-4.8$ & 0.003 \\
\hline IL-10 (ng/l) & $1.5^{\star} /-2.1$ & $1.6^{*} /-3.2$ & 0.8 \\
\hline GM-CSF (ng/l) & $1.2^{*} /-2.0$ & $1.4^{\star} /-3.6$ & 1.0 \\
\hline IFN- $\gamma(\mathrm{ng} / \mathrm{l})$ & $1.4^{*} /-3.0$ & $1.6^{\star} /-4.0$ & 0.6 \\
\hline TNF- $\alpha(\mathrm{ng} / \mathrm{l})$ & $1.4^{*} /-2.1$ & $1.3^{*} /-2.5$ & 0.03 \\
\hline Ghrelin $(\mu \mathrm{g} / \mathrm{l})$ & $0.73(0.40-2.22)$ & $1.12(0.56-1.91)$ & $<0.0005$ \\
\hline Insulin (pmol/l) & $32(10-119)$ & $32(7-80)$ & 0.8 \\
\hline $\begin{array}{l}\text { Glucose } \\
\quad(\mathrm{mmol} / \mathrm{l})\end{array}$ & $4.72^{*} /-0.85$ & $4.47^{\star} /-0.36$ & $0.04^{\dagger \dagger}$ \\
\hline HOMA-index & $0.68(0.19-2.44)$ & $0.65(0.15-1.68)$ & 0.7 \\
\hline Leptin $(\mu \mathrm{g} / \mathrm{l})$ & $15.3^{*} /-1.9$ & $11.4^{*} /-1.9$ & 0.02 \\
\hline
\end{tabular}

IL, interleukin; GM-CSF, granulocyte-macrophage Colony-stimulating factor; IFN, interferon; TNF, tomor necrosis factor; HOMA, homeostatic model assessment.

${ }^{\dagger}$ Mann-Whitney test, unless otherwise indicated. ${ }^{\dagger+}$ Unpaired students $t$-test. 
Table 4 Sex hormones, insulin-like growth factors (IGFs) and endothelial markers in Tumer syndrome (TS) patients and controls (mean \pm s.D. or median and range).

\begin{tabular}{lccc}
\hline & $\begin{array}{c}\text { TS } \\
(n=54)\end{array}$ & $\begin{array}{c}\text { Controls } \\
(n=55)\end{array}$ & $\boldsymbol{P}^{*}$ \\
\hline $\begin{array}{c}\text { Estradiol } \\
(\mathrm{nmol} / \mathrm{l})\end{array}$ & $0.23(0.06-0.89)$ & $0.24(0.06-1.09)$ & 0.9 \\
$\begin{array}{c}\text { Testosterone } \\
(\mathrm{nmol} / \mathrm{l})\end{array}$ & $0.77(0.04-5.42)$ & $1.37(0.39-4.89)$ & $<0.0005$ \\
$\begin{array}{c}\mathrm{SHBG} \\
(\mathrm{nmol} / \mathrm{l})\end{array}$ & $74(8-193)$ & $117(64-421)$ & $<0.0005$ \\
$\begin{array}{l}\text { ICAM-I }(\mu \mathrm{g} / \mathrm{l}) \\
\text { VCAM-I }\end{array}$ & $235(145-512)$ & $211(77-436)$ & 0.02 \\
$\quad(\mu \mathrm{g} / \mathrm{l})$ & $292(150-456)$ & $295(159-477)$ & 0.9 \\
$\begin{array}{l}\text { IGF-I }(\mu \mathrm{g} / \mathrm{l}) \\
\text { IGFBP-3 } \\
(\mu \mathrm{g} / \mathrm{l})\end{array}$ & $120(67-244)$ & $174(78-252)$ & $<0.0005^{\dagger}$ \\
\hline
\end{tabular}

SHBG, sex hormone-binding globolin; ICAM, intercelluar cell adhesion molecule; IGFBP, IGF binding protein

*Mann-Whitney test, unless otherwise indicated. 'Unpaired Student's $t$-test.

A

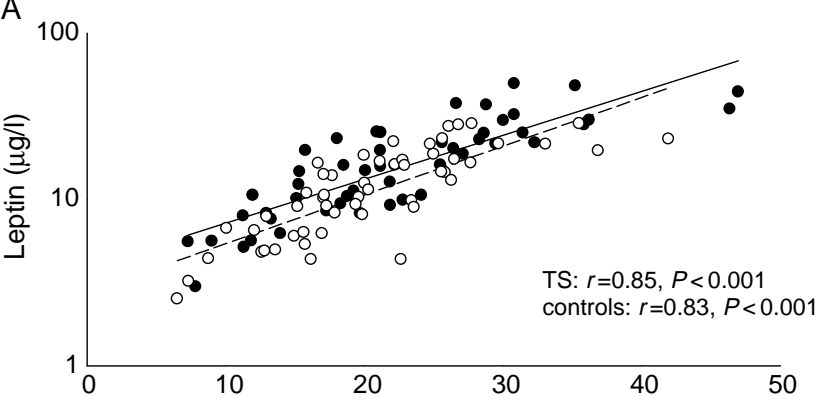

B

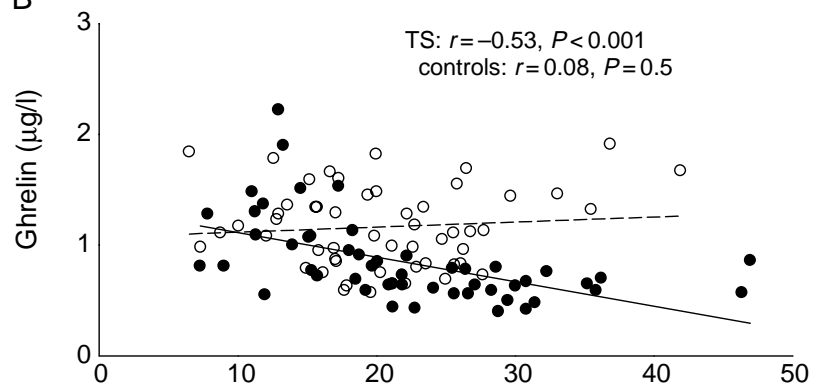

C

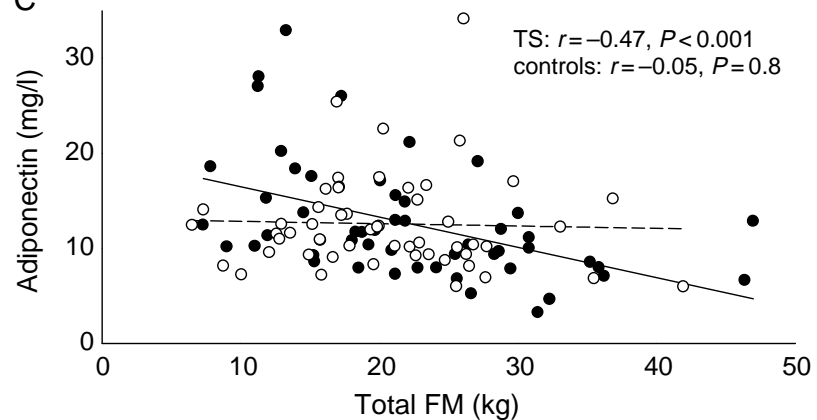

Figure 3 The relationship between total fat mass (FM) and (A) leptin, (B) ghrelin and (C) adiponectin in TS ( and - ) and controls ( $O$ and ----). Regression coefficients and significance levels are indicated in each graph.
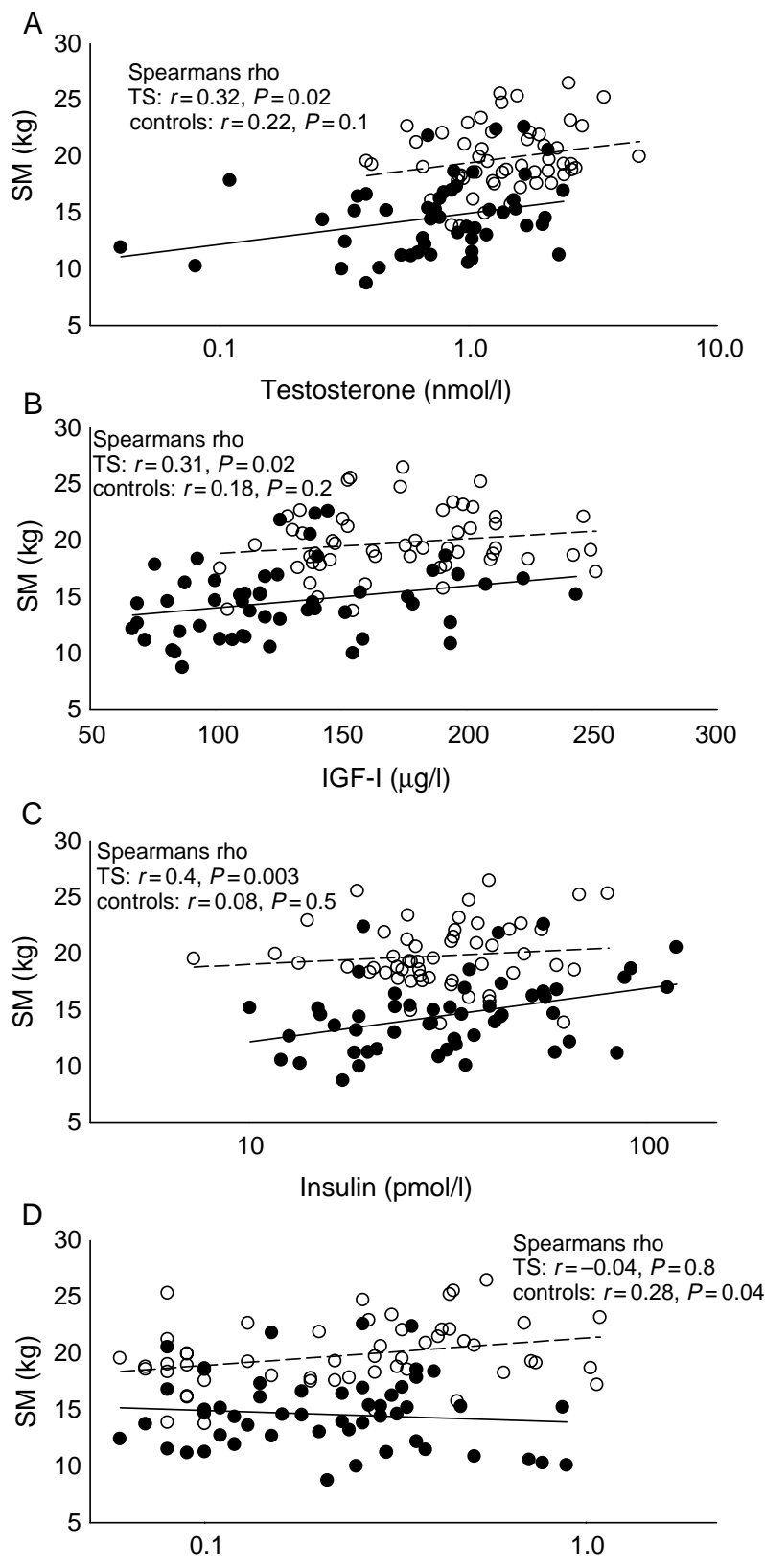

Estradiol (nmol/l)

Figure 4 The relationship between skeletal muscle mass (SM) and (A) testosterone, (B) insulin-like growth factor (IGF-I), (C) insulin, and (D) estradiol in TS ( $\bigcirc$ and - ) and controls ( $O$ and ----). Regression coefficients and significance levels are indicated in each graph. Note that the axes for testosterone, insulin, and estradiol are logarithmically transformed.

In TS, IGFBP-3 and insulin were also positively correlated with total FM and other measures of adiposity (all $P<0.01$ ), and SHBG correlated negatively with measures of adiposity $(P<0.01)$. Again, in controls, only insulin showed a weak significant positive correlation with measures of adiposity $(P<0.05)$. 


\section{Relationship between cytokines, endothelial markers, and insulin sensitivity}

There were no significant correlations between inflammatory and endothelial markers, except for a positive correlation between VCAM-I and IL-8 $(P<0.01)$ in TS.

Likewise, there were no significant correlations between measures of glucose homeostasis and markers of endothelial function or between measures of glucose homeostasis and cytokines, except for a significant correlation between IL-6 and HOMA-index $(r=0.3$, $P=0.02)$ in TS.

\section{Determinants of body composition}

The principal determinants of body composition were evaluated by backward multiple linear regression with measures of body composition as dependent and independent variables, we chose significant variables from the Spearman's correlation analyses above.

In a multivariate model $(r=0.88, P<0.001)$ with total FM in TS as the dependent variable, leptin $(P<0.001)$, IGF-I $(P=0.002)$, IGFBP-3 $(P=0.003)$, SHBG $(P=0.01)$, and ghrelin $(P=0.08)$ were all explanatory variables. Studying the same model in controls $(r=0.79, P<0.001)$ only leptin was a significant explanatory variable.

In a multivariate model $(r=0,82, P<0.001)$ with visceral FM in TS as the dependent variable, leptin $(P<0.001)$, IGF-I and IGFBP-3 (both $P=0.03)$, HOMAindex $(P=0.08)$, and SHBG $(P=0.1)$ were significant explanatory variables, while in controls $(r=0.74$, $P<0.001)$, leptin $(P<0.001)$, adiponectin $(P=0.05)$, and SHBG $(P=0.1)$ were explanatory variables.

The principal determinants of IMAT SM $(r=0.63$, $P<0.001)$ in TS were testosterone $(P=0.004)$, leptin
$(P=0.01)$ and ghrelin $(P=0.04)$, and among controls in a similar regression model $(r=0.42, P=0.02)$ leptin $(P=0.02)$, insulin $(P=0.03)$, and estradiol $(P=0.05)$ were significant explanatory variables. Multiple regression models with other indices of adiposity and LBM gave essentially similar results.

In combined multiple regression models, where status (i.e. being TS or control) was included, status was consistently one of the major contributing variables. For example, in a model with IMAT SM $(r=0.86, P<0.001)$ as the dependent variable, status, $\mathrm{VO}_{2 \max }$, HOMA-index, and IGFBP-3 were independent explanatory variables (Table 5). In another model, with total FM as the dependent variable $(r=0.84, P<0.001)$, leptin, IGF-I, status, $\mathrm{VO}_{2 \text { max }}$, $\mathrm{SHBG}$, and HOMA-index were significant explanatory variables. In a model with visceral FM $(r=$ $0.78, P<0.001)$, leptin, status, SHBG, IGF-I, HOMAindex, and adiponectin were significant variables.

\section{Discussion}

The present data show that body composition in TS is profoundly changed. Numerous factors seem to influence the decreased LBM and the increased FM, such as sex hormones, the growth hormone (GH)/IGF system, maximal oxygen uptake (or physical fitness), insulin sensitivity, ghrelin and leptin, and possibly other factors. However, the syndrome per se is also likely to contribute. The study extends the results of previous studies into the realm of regional body composition, and it is clear that in addition to disproportional anthropometrics and bone $(6,7,17,30)$, one must also include the content and the distribution of adipose tissue and muscle mass.

Table 5 Parameters correlated to measures of body composition (backwards multiple linear regression including all participants with Tumer syndrome (TS) and controls).

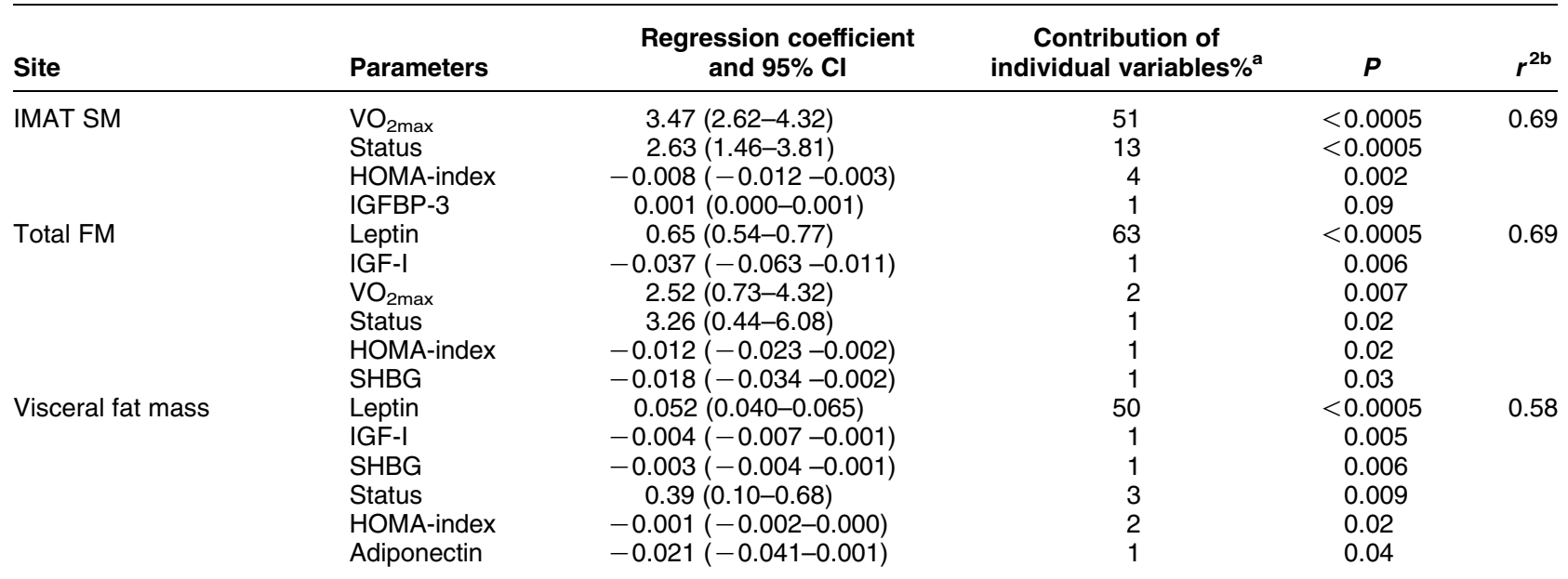

IMAT SM, intermuscular adipose tissue-free skeletal muscle mass; status, being TS or a control; $\mathrm{VO}_{2 \max }$, maximal oxygen uptake; HOMA-index, insulin sensitivity index; SHBG, sex hormone-binding globulin; IGF-I, insulin-like growth factor I; IGFBP-3, IGF-binding protein-3.

${ }^{a}$ The contribution of individual variables to the adjusted squared correlation coefficient. Computed by removing variables stepwise, and given as a percentage.

${ }^{\mathrm{b}}$ Adjusted squared correlation coefficient (i.e. for IMAT SM, the correlation explains $69 \%$ of the total variation). 
We investigated a range of biochemical markers, previously associated with indices of body composition in other studies, in a group of women with TS covering a wide age range with an age-matched control group. This approach was chosen in order to study both total and regional body composition in more detail than in previous studies, and subsequently determine possible determinants of the abnormal body composition.

As found previously in adults, we found normal fasting insulin sensitivity using the HOMA-index (12, $13,31)$ although fasting glucose was slightly elevated. Maximal oxygen uptake was decreased, as was a selfreported index of physical activity, as described previously $(4,31)$, and since we found a close correlation between measured maximal oxygen uptake and self-reported activity, we conclude that women with TS lead a more sedentary life-style than the controls. We also found a close correlation between FM and insulin sensitivity.

We recorded distinct changes in body composition, with increased amounts of body fat, even after adjustment for differences in BMI. We made no formal attempt to match TS and controls on BMI. This approach was chosen since we previously documented a skewed body composition in adolescent aged 9-14 (6) and 13-18 years ( 7 ), despite a BMI comparable to controls in these two studies. In most regression analyses, we could show that IGF-I and IGFBP-3, testosterone and estradiol, SHBG, ghrelin and leptin were determinants of both measures of adiposity but also of SM. In combined regression analyses the picture was similar, but in addition, $\mathrm{VO}_{2 \max }$ and status were also contributing variables. This does not in anyway prove causality between the examined variables, but the fact that the dichotomous variable 'status' in all combined regression analyses was a contributing variable indicates that body composition seems to be influenced significantly by having TS, and as such, the results indicate that body composition is distinctly altered in TS. These alterations not only apply to the amount of both FM and LBM, but also to the observed distinct regional differences. From the correlation analyses, it can be deduced that there seems to be not only a resistance to the anabolic effect of IGF-I, but also the anabolic effects of testosterone, insulin, and estradiol. For any given level of these hormones, the SM was higher in controls compared with TS. Previously, GH and IGF-I resistance has been proposed (32) and indirectly proved by the fact that TS girls need GH and IGF-I levels well into the acromegalic range to grow properly (33). We have suggested a reduced bioactivity of the GH-IGF-IGFBP axis (34), perhaps also influencing the cross-talk between GH/IGFI and testosterone, not only at the level of the hypothalamus, but also peripherally, where GH/IGF-I and follicle-stimulating hormone and luteinizing hormone (LH) synergize in stimulating ovarian steroidogenesis (35), and a synergistic effect on protein anabolism is also present (36). It is therefore difficult to state whether a degree of estradiol/testosterone resistance is also present in TS or the seemingly reduced effect of testosterone is merely due to reduced GH/IGF-I bioactivity. In fact, the universal reductions of several axes may synergize to form a vicious cycle further perturbing body composition, and suggest that only proper supplementation of not only estradiol (and progesterone), but also testosterone and GH/IGF-I may normalize the hormonal milieu, and thereby body composition. GH treatment in TS girls leads to robust increases in muscle mass and normalizes the amount of body fat $(6,37)$. The distribution of fat and muscle was also discordant with accumulation of both the trunk (a mixture of subcontaneous and visceral FM) and visceral FM determined by DEXA. This is interesting because accumulation of visceral fat in other settings predicts higher risk of insulin resistance, dyslipidemia, cardiovascular disease, hypoandrogenemia, elevated cortisol, and reductions in SHBG, IGFBP-1, LH, high density lipoprotein-cholesterol, and GH production, in other words, a high risk of the insulin resistance syndrome $(38,39)$. In a small study of TS utilizing MRI, a similar picture of body composition was present, and in addition, it was shown that fat accumulation in the liver was also present, the latter related to estrogen exposure (8).

Inflammatory cytokines such as IL-6, IL-8, and TNF- $\alpha$ were discretely, but significantly elevated in TS, while other cytokines, as well as adiponectin were comparable in the two study groups. Combined with previous studies showing slightly elevated levels of CRP (18) and IL-6 (17), a picture of a chronic low-grade inflammatory state emerges. None of the cytokines were related to body composition. Surprisingly, adiponectin was not decreased as would have been expected for the given level of adiposity.

SM and LBM was highly significantly reduced, similar to findings in pre-pubertal and pubertal girls $(6,7)$. In a longitudinal study of pre-pubertal girls, LBM $z$-score (age, but not height or weight adjusted) was found to be reduced, but due to the presentation of data it is not clear whether LBM was genuinely reduced if adjustment for differences in body size had been performed (40). In a study of forearm bone density by peripheral quantitative computed tomography, cross-sectional muscle area was found to be comparable to controls (41). Since skeletal muscle mass correlated positively with $\mathrm{VO}_{2 \max }$ and physical activity, as well as with IGF and testosterone, it seems prudent to state that the reason for the reduced muscle mass is multi-factorial and that the syndrome per se contributes to the reduction.

Circulating ICAM-1 was increased, while the level of VCAM-I was normal in TS. Increased plasma concentrations of both VCAM-1 and ICAM-1 have been linked to several vascular-related conditions, such as coronary artery disease, hypertension, and type 2 diabetes (42). Whether elevated ICAM-I in TS may reflect an early marker of vascular involvement remains to be seen. 
The cross-sectional nature of the present study precludes most conclusions on causality. However, the fact that the parameter 'status' in all multiple linear regression models of body composition is a significant contributor to the observed differences between TS and control women, suggests that the genotype, i.e. having TS, could explain a large part of the observed differences. The consequences of a given genotype (i.e. TS) materializes long before the present measurements and can be viewed as a stable marker of host susceptibility enabling one to draw cautious conclusions regarding causality even from studies with a cross-sectional design (43). Pivotal to the interpretation of the present data is the use of an algorithm to determine SM and the application of a new region of interest on the DEXA scans to determine visceral FM. The algorithm is derived from studies of normal women and, as such, not validated in TS and this also applies to the determination of visceral FM. When studying small patient groups like those in the present study, it is almost impossible to validate most methodologies, since such an approach would be very time-consuming, and the patient material is always very limited. Therefore, one has to rely on or assume that algorithms developed in normal groups of individuals can be reasonably applied. We cannot determine the size of any error introduced by the use of these methods, but we have previously shown that DEXA readily picks up important changes during GH treatment in TS $(6,7)$, and it is likely, but not proven that the application of DEXA is methodologically sound in TS.

In summary, profound changes are present in body composition in adult women with TS, with marked regional changes, increased FM, and decreased SM. Circulating hormones, $\mathrm{VO}_{2 \max }$, and insulin sensitivity influence body composition. The accumulation of visceral fat, in conjunction with the recorded changes in circulating hormones, would predict a higher risk of development of the insulin resistance syndrome.

\section{Acknowledgements}

Lone Svendsen, Joan Hansen, Kirsten Hald, Charlotte Gylling, Tove Stenum, and Donna Arbuckle Lund are thanked for expert technical help. The study was supported by a grant from the Danish Health Research Council, grant number 9600822 (Århus University Novo Nordisk Center for Research in Growth and Regeneration), the Novo Nordisk Foundation and Clinical Institute, Aarhus University Hospital.

\section{References}

1 Park E. Body shape in Turner's syndrome. Human Biology 197749 215-223.

2 Varrela J, Vinkka H \& Alvesalo L. The phenotype of 45,X females: an anthropometric quantification. Annals of Human Biology 1984 11 53-66.
3 Gravholt CH \& Naeraa RW. Reference values for body proportions and body composition in adult women with Turner's syndrome. American Journal of Medical Genetics 199772 403-408.

4 Gravholt CH, Naeraa RW, Fisker S \& Christiansen JS. Body composition and physical fitness are major determinants of the growth hormone-IGF axis aberrations in adult Turner syndrome, with important modulations by treatment with 17-betaestradiol. Journal of Clinical Endocrinology and Metabolism 1997 82 2570-2577.

5 Holl RW, Kunze D, Etzrodt H, Teller W \& Heinze E. Turner syndrome: final height, glucose tolerance, bone density and psychosocial status in 25 adult patients. European Journal of Pediatrics 1994153 11-16.

6 Gravholt CH, Naeraa RW, Brixen K, Kastrup KW, Mosekilde L, Jørgensen JO \& Christiansen JS. Short term growth hormone treatment in girls with Turner syndrome decreases fat mass and insulin sensitivity. A randomized double-blind, placebo-controlled cross-over study. Pediatrics $2002110889-896$.

7 Gravholt CH, Hjerrild BE, Naeraa RW, Engbaek F, Mosekilde L \& Christiansen JS. Effect of growth hormone and 17beta-oestradiol treatment on metabolism and body composition in girls with Turner syndrome. Clinical Endocrinology 200562 616-622.

8 Ostberg JE, Thomas EL, Hamilton G, Attar MJ, Bell JD \& Conway GS. Excess visceral and hepatic adipose tissue in Turner syndrome determined by magnetic resonance imaging: estrogen deficiency associated with hepatic adipose content. Journal of Clinical Endocrinology and Metabolism 200590 2631-2635.

9 Gravholt CH, Juul S, Naeraa RW \& Hansen J. Morbidity in Turner syndrome. Journal of Clinical Epidemiology 199851 147-158.

10 Caprio S, Boulware S, Diamond M, Sherwin RS, Carpenter TO, Rubin K, Amiel S, Press M \& Tamborlane WV. Insulin resistance: an early metabolic defect of Turner's syndrome. Journal of Clinical Endocrinology and Metabolism 199172 832-836.

11 Stoppoloni G, Prisco F, Alfano C, Iafusco D, Marrazzo G \& Paolisso G. Characteristics of insulin resistance in Turner syndrome. Diabetes Metabolism 199016 267-271.

12 Gravholt CH, Naeraa RW, Nyholm B, Gerdes U, Christiansen E, Schmitz O \& Christiansen JS. Glucose metabolism, lipid metabolism, and cardiovascular risk factors in adult Turner syndrome: the impact of sex hormone replacement. Diabetes Care 199821 1062-1070.

13 Bakalov VK, Cooley MM, Quon MJ, Luo ML, Yanovski JA, Nelson LM, Sullivan G \& Bondy CA. Impaired insulin secretion in the Turner metabolic syndrome. Journal of Clinical Endocrinology and Metabolism 200489 3516-3520.

14 Stochholm K, Juul S, Juel K, Naeraa RW \& Gravholt CH. Prevalence, incidence, diagnostic delay, and mortality in Turner syndrome. Journal of Clinical Endocrinology and Metabolism 2006 (Epub ahead of print).

15 Sybert VP. Cardiovascular malformations and complications in Turner syndrome. Pediatrics 1998101 E11-E17.

16 Ho VB, Bakalov VK, Cooley M, Van PL, Hood MN, Burklow TR \& Bondy CA. Major vascular anomalies in turner syndrome: prevalence and magnetic resonance angiographic features. Circulation $20041101694-1700$.

17 Ostberg JE, Attar MJ, Mohamed-Ali V \& Conway GS. Adipokine dysregulation in Turner syndrome: comparison of circulating interleukin-6 and leptin concentrations with measures of adiposity and C-reactive protein. Journal of Clinical Endocrinology and Metabolism $2005902948-2953$.

18 Gravholt CH, Leth-Larsen R, Lauridsen AL, Thiel S, Hansen TK, Holmskov U, Naeraa RW \& Christiansen JS. The effects of GH and hormone replacement therapy on serum concentrations of mannan-binding lectin, surfactant protein $\mathrm{D}$ and vitamin $\mathrm{D}$ binding protein in Turner syndrome. European Journal of Endocrinology 2004150 355-362.

19 Åstrand I. A method for prediction of aerobic work capacity for females and males of different ages. Acta Physiologica Scandinavica 196049 45-60. 
20 Lindgarde F \& Saltin B. Daily physical activity, work capacity and glucose tolerance in lean and obese normoglycaemic middle-aged men. Diabetologia 1981 $20134-138$.

21 Saltin B \& Grimby G. Physiological analysis of middle-aged and old former athletes. Comparison with still active athletes of the same ages. Circulation 196838 1104-1115.

22 Carey DG, Jenkins AB, Campbell LV, Freund J \& Chisholm DJ. Abdominal fat and insulin resistance in normal and overweight women: direct measurements reveal a strong relationship in subjects at both low and high risk of NIDDM. Diabetes $1996 \mathbf{4 5}$ 633-638.

23 Ross R, Shaw KD, Martel Y, de Guise J \& Avruch L. Adipose tissue distribution measured by magnetic resonance imaging in obese women. American Journal of Clinical Nutrition $1993 \mathbf{5 7} 470-475$.

24 Heymsfield SB, Smith R, Aulet M, Bensen B, Lichtman S, Wang J \& Pierson RN Jr. Appendicular skeletal muscle mass: measurement by dual-photon absorptiometry. American Journal of Clinical Nutrition $1990 \mathbf{5 2} 214-218$.

25 Kim J, Heshka S, Gallagher D, Kotler DP, Mayer L, Albu J, Shen W, Freda PU \& Heymsfield SB. Intermuscular adipose tissue-free skeletal muscle mass: estimation by dual-energy X-ray absorptiometry in adults. Journal of Applied Physiology 200497 655-660.

26 Abrahamsen B, Gram J, Hansen TB \& Beck NH. Cross calibration of QDR-2000 and QDR-1000 dual-energy X-ray densitometers for bone mineral and soft-tissue measurements. Bone 199516 385-390.

27 Espelund U, Hansen TK, Ørskov H \& Frystyk J. Assessment of ghrelin. APMIS Supplementum 2003109 140-145.

28 Hoybye C, Bruun JM, Richelsen B, Flyvbjerg A \& Frystyk J. Serum adiponectin levels in adults with Prader-Willi syndrome are independent of anthropometrical parameters and do not change with GH treatment. European Journal of Endocrinology 2004151 457-461.

29 Hansen TK, Thiel S, Wouters PJ, Christiansen JS \& Van den BG. Intensive insulin therapy exerts antiinflammatory effects in critically ill patients and counteracts the adverse effect of low mannose-binding lectin levels. Journal of Clinical Endocrinology and Metabolism $2003 \mathbf{8 8} 1082-1088$.

30 Gravholt CH, Lauridsen AL, Brixen K, Mosekilde L, Heickendorff L \& Christiansen JS. Marked dysproportionality in bone size and mineral, and distinct abnormalities in bone markers and calcitropic hormones in adult Turner syndrome. A cross-sectional study. Journal of Clinical Endocrinology and Metabolism 200287 2798-2808.

31 Landin-Wilhelmsen K, Bryman I \& Wilhelmsen L. Cardiac malformations and hypertension, but not metabolic risk factors, are common in Turner syndrome. Journal of Clinical Endocrinology and Metabolism 200186 4166-4170.

32 Gravholt $\mathrm{CH}$. Epidemiological, endocrine and metabolic features in Turner syndrome. European Journal of Endocrinology 2004151 657-687.
33 Van Pareren YK, de Muinck Keizer-Schrama SM, Stijnen T, Sas TC, Jansen M, Otten BJ, Hoorweg-Nijman JJ, Vulsma T, Stokvis-Brantsma WH, Rouwe CW, Reeser HM, Gerver WJ, Gosen JJ, Rongen-Westerlaken C \& Drop S. Final height in girls with Turner syndrome after long-term growth hormone treatment in three dosages and low dose estrogens. Journal of Clinical Endocrinology and Metabolism $2003 \mathbf{8 8} 1119-1125$.

34 Gravholt CH, Frystyk J, Flyvbjerg A, Ørskov H \& Christiansen JS. Reduced free IGF-I and increased IGFBP-3 proteolysis in Turner syndrome: modulation by female sex steroids. American Journal of Physiology $20012 \mathbf{2 8 0}$ E308-E314.

35 Burks DJ, Font dM, Schubert M, Withers DJ, Myers MG, Towery HH, Altamuro SL, Flint CL \& White MF. IRS-2 pathways integrate female reproduction and energy homeostasis. Nature $2000 \mathbf{4 0 7} 377-382$.

36 Veldhuis JD, Roemmich JN, Richmond EJ, Rogol AD, Lovejoy JC, Sheffield-Moore M, Mauras N \& Bowers CY. Endocrine control of body composition in infancy, childhood, and puberty. Endocrine Reviews 200526 114-146.

37 Leger J, Carel C, Legrand I, Paulsen A, Hassan M \& Czernichow P. Magnetic resonance imaging evaluation of adipose tissue and muscle tissue mass in children with growth hormone (GH) deficiency, Turner's syndrome, and intrauterine growth retardation during the first year of treatment with GH. Journal of Clinical Endocrinology and Metabolism 199478 904-909.

38 Fernandez-Real JM \& Ricart W. Insulin resistance and chronic cardiovascular inflammatory syndrome. Endocrine Reviews 2003 24 278-301.

39 Pijl H, Langendonk JG, Burggraaf J, Frolich M, Cohen AF, Veldhuis JD \& Meinders AE. Altered neuroregulation of $\mathrm{GH}$ secretion in viscerally obese premenopausal women. Journal of Clinical Endocrinology and Metabolism 200186 5509-5515.

40 Hogler W, Briody J, Moore B, Garnett S, Lu PW \& Cowell CT. Importance of estrogen on bone health in turner syndrome: a cross-sectional and longitudinal study using dual-energy X-ray absorptiometry. Journal of Clinical Endocrinology and Metabolism 200489 193-199.

41 Bechtold S, Rauch F, Noelle V, Donhauser S, Neu CM, Schoenau E \& Schwarz HP. Musculoskeletal analyses of the forearm in young women with Turner syndrome: a study using peripheral quantitative computed tomography. Journal of Clinical Endocrinology and Metabolism 200186 5819-5823.

42 Blankenberg S, Barbaux S \& Tiret L. Adhesion molecules and atherosclerosis. Atherosclerosis 2003 170 191-203.

43 Khoury MJ. Genetic epidemiology. In Modern Epidemiology, pp 609-621. Eds KJ Rothman \& S Greenland, Philadelphia: Lippincott-Raven, 1998.

Received 16 June 2006

Accepted 27 July 2006 